\title{
A Aplicação do QFD no Desenvolvimento de Software: Um Estudo de Caso
}

\author{
Fernando Antônio Sonda, Ph.D. Informática \\ Rua Moreira César, 1903 - 95034-000 - Caxias do Sul - RS \\ phdinfo@zaz.com.br
}

José Luis Duarte Ribeiro

Programa de Pós Graduaçāo em Engenharia de Produção - UFRGS

Praça Argentina 9, sala 402 - 90040-020 - Porto Alegre - RS

ribeiro@vortex.ufrgs.br

Márcia Elisa Echeveste
Programa de Pós Graduação em Engenharia de Produção - UFRGS
Praça Argentina 9, sala 402 - 90040-020 - Porto Alegre - RS
echevest@ppgep.ufrgs.br

Resumo

Este trabalho tem como objetivo apresentar a aplicação do QFD como ferramenta de suporte para o planejamento e desenvolvimento de um software de custos, visando um melhor atendimento das características demandadas pelo cliente, bem como a determinação de indicadores para controlar o processo de desenvolvimento do produto. $\mathrm{O}$ trabalho foi desenvolvido a partir de uma pesquisa de mercado realizada com usuários de softwares de custos e demais pessoas envolvidas com o gerenciamento de custos. Com a aplicaçāo do QFD, observou-se que a definiçāo antecipada das características principais do sistema é fundamental para o desenvolvimento de um software. O QFD vem se somar as demais ferramentas de análise de sistemas proporcionando, simultaneamente, um desenvolvimento mais rápido e mais qualificado.

Palavras-chave: pesquisa de mercado, qualidade, QFD, software, custos.

\section{Abstract}

This paper presents an application of QFD for planning and development of a cost software. The QFD was chosen aiming a better assessment of the user desires as well as the indication of the parameters for process control. The work was initiated from a market survey conducted on users of cost software and other people involved in cost management. The use of the QFD shows that the early definition of the key characteristics of the system is essential in software development. The QFD complements the use of other system analysis techniques and contributes for a faster and more qualified software development.

Keywords: market survey, quality, QFD, software, cost.

\section{1 - Introdução}

A velocidade das informações e as novas tecnologias estabeleceram um ambiente globalizado de alta concorrência, onde preço, prazo, qualidade e flexibilidade precisam ser atendidos. As empresas devem trabalhar continuamente para que o cliente esteja satisfeito e volte a comprar o seu produto. Neste ambiente, as pessoas ganham maior importância, pois precisam ser atendidas rapidamente, com o produto certo. Assim, o gerenciamento orientado para o cliente é a solução para a sobrevivência das empresas no mercado.

Essa realidade é particularmente verdadeira na indústria da informática. Atualmente, computadores e processadores estão presentes na maioria dos escritórios e estão sendo rapidamente incorporados a todas as tecnologias. Assim, as pessoas passam a conviver com softwares, os quais vêm se constituído nos componentes centrais em muitas atividades complexas. Na medida em que aumenta a dependência relativa a softwares, cresce a

Sonda, F. A., Ribeiro, J. L. D., Echeveste - A Aplicaçāo do QFD no Desenvolvimento de Softrware: Um Estudo de Caso 
PRODUÇÃO

demanda por produtos de alta qualidade, desenvolvidos de acordo com as necessidades dos clientes. O desenvolvimento de softwares exige a utilização de ferramentas e técnicas especializadas.

A importância crescente do desenvolvimento de software é confirmada pelo tratamento diferenciado recebido nas normas de qualidade. A ISO 9000, que estabelece um padrão para a gestão e garantia da qualidade, em sua parte 3 apresenta diretrizes para a aplicação da ISO 9001 ao desenvolvimento, fornecimento e manutenção de softwares.

De acordo com Usrey \& Dooley, 1996, no desenvolvimento de software, os fatores críticos são os seguintes: (i) desempenho superior as expectativas; (ii) facilidade de uso e facilidade de interação; (iii) utilidade atual (qualidade percebida); e (iv) utilidade futura (flexibilidade). Em um outro artigo, Usrey \& Dooley, 1998, abordam a avaliação da atitude do usuário referente a softwares. Eles enfatizam a necessidade e urgência em entender, controlar e planejar a qualidade do software.

Enquanto isso, Dale \& Machowski, 1999, discutem os custos de qualidade associados ao desenvolvimento de softwares. Esses autores concluem afirmando que os esforços devem ser concentrados na coleta de informações qualificadas referentes a definição do produto (fases iniciais de desenvolvimento do software). Mais ainda, eles sugerem o uso de FMEA (Failure Mode and Effect Analysis ou Análise de Modos e Efeitos de Falha) e do QFD como técnicas efetivas para qualificar o desenvolvimento de softwares.

O QFD - Quality Function Deployment, ou Desdobramento da Função Qualidade - iniciou no Japão no final dos anos 60 e atualmente é utilizado pela metade das grandes empresas japonesas (Ghiya et al., 1999). No início dos anos 80 , ele foi introduzido na indústria automotiva americana e atualmente é usado por muitas empresas deste setor. O QFD representa um esforço para conseguir que o ponto de vista do cliente referente a qualidade seja incorporado nas fases iniciais do desenvolvimento e continue sendo considerado ao longo de todo o ciclo de vida do produto. Pode ser dito que o QFD representa uma mudança do controle de qualidade focado em manufatura e processo para o controle de qualidade voltado para o desenvolvimento do produto (Sullivan, 1986). Segundo King (1987), o QFD é uma ferramenta multifuncional que permite às organizações priorizarem as demandas dos consumidores e, em função disso, desenvolverem resposta inovadoras para as necessidades dos clientes, que sejam efetivas em termos de custo e qualidade. O mesmo autor afirma que o QFD pode direcionar uma implementação bem sucedida de um novo produto ou processo, na medida em que envolve todos os departamentos: marketing, pesquisa e desenvolvimento, produção, controle de qualidade, vendas e serviços, etc.

Segundo Akao (1997), o QFD consiste em converter as demandas dos consumidores em características de qualidade e em desenvolver um projeto de qualidade para um produto acabado, desdobrando as relações entre demandas e características. Este desdobramento começa com a qualidade de cada componente funcional e se estende para a qualidade de cada parte ou processo. A qualidade total do produto será entendida através de uma rede de relações.

Segundo Gustafsson \& Johnson, 1997, o QFD é uma ferramenta que pode auxiliar as empresas a vencerem a lacuna que existe entre a satisfação do cliente e o desenvolvimento de qualidade em produtos e processos. O QFD auxilia as empresas a serem competitivas, na medida em que acelera o desenvolvimento do produto considerando explicitamente as demandas do cliente.

Ouvir os clientes é essencial, no entanto nem sempre é fácil traduzir para os produtos ou serviços os desejos dos consumidores, pois muitas vezes a linguagem utilizada não se adapta diretamente às especificações técnicas. O QFD contribui para vencer essas dificuldades. $\mathrm{Na}$ realidade, o QFD é um método de gerenciamento interfuncional, para auxiliar na garantia da qualidade de processos, produtos e serviços.

O QFD também contribui na redução de custos, pois tem sua tônica no planejamento do processo. Sendo 
assim o produto final sai com pouca ou quase nenhuma chance de perda ou retrabalho face a problemas de projeto, pois decisões de mudança podem ser realizadas ainda na fase de projeto, tendo uma forte ligação com o desenvolvimento das estratégias de marketing.

\section{2 - Descrição do problema e método de trabalho}

A Ph.D. Informática é uma pequena softwarehouse situada em Caxias do Sul, um dos principais polos industriais do estado do Rio Grande do Sul. Sua principal atividade é desenvolver soluções personalizadas às necessidades dos seus clientes e assessorá-los no uso de tecnologias de informática. A empresa vem desenvolvendo sistemas para atender diversas empresas regionais.
Como o faturamento da Ph.D. atualmente provém basicamente da venda de horas técnicas, a mesma está estudando a possibilidade de ingressar no mercado com um produto padrão e está avaliando a possibilidade de desenvolver um sistema avançado de gerenciamento de custos, capaz de suprir às necessidades atuais de seus clientes.

Para auxiliar no desenvolvimento do sistema, a empresa optou pelo uso do QFD, uma técnica que explicitamente busca levantar as necessidades do clientes e incorporá-las no projeto do produto e nos processos de produção.

As etapas que compõe o desdobramento da qualidade variam conforme a aplicação. Neste trabalho, o desdobramento irá contemplar o seguinte: (i) Pesquisa de mercado; (ii) Matriz da qualidade, (iii) Matriz das partes, (iv) Matriz das características das partes, (v) Matriz do

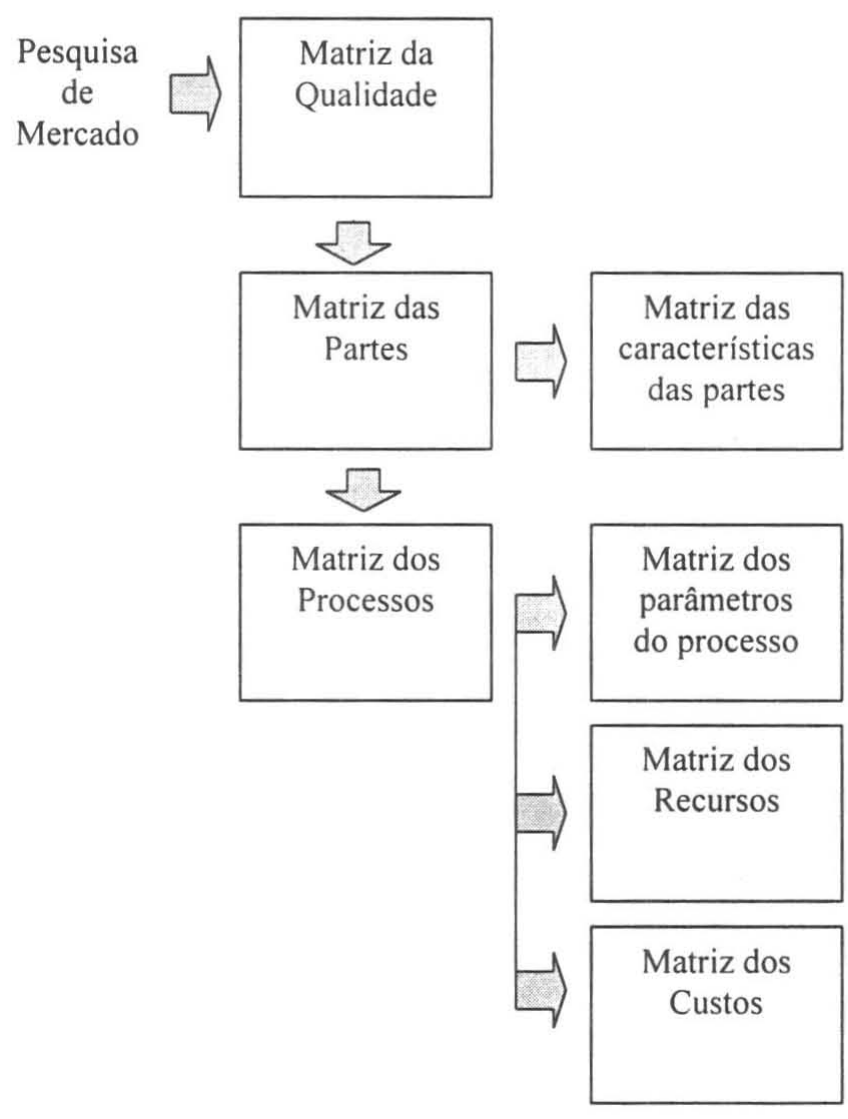

Figura 1: Modelo Conceitual utilizado no estudo de caso. 
PRODUÇÃO =

processo; (vi) Matriz dos parâmetros do processo; (vii) Matriz dos recursos; (viii) Matriz dos custos; e (ix) Planejamento das melhorias. O modelo conceitual utilizado aparece na Figura 1. O estudo de caso será apresentado nas seções a seguir. A apresentação está organizada de acordo com a lista anterior.

O método de trabalho, utilizado neste estudo, envolveu quatro etapas: (i) treinamento em QFD, visando nivelar os participantes da equipe técnica, (ii) pesquisa de mercado, visando reunir as informações necessárias para dar início ao desdobramento; (iii) reuniões regulares ao longo de um mês para o preenchimento gradativo de todas as matrizes; e (iv) definição do plano de melhoria da qualidade, efetuado a partir dos resultados obtidos em todas as etapas do QFD.

\section{3 - Pesquisa de Mercado}

Segundo Breen e Blankenship apud YUKI, 1994, a falta de conhecimento dos produtos ou serviços a serem vendidos é uma das principais (e óbvias) razões do fracasso de pequenas empresas varejistas e de serviços. No atual nível de competitividade, a informação é o elemento fundamental para o sucesso empresarial. Assim, as empresas devem buscar o conhecimento da situação do mercado e dos consumidores, identificando as oportunidades existentes. No que se refere ao software de custos, trata-se de um produto a ser lançado. As informações disponíveis na empresa não respondem às questões básicas para a tomada de decisões. Assim, optou-se por realizar uma pesquisa de mercado, buscando reunir dados para a definição da qualidade demandada, ponto de partida para o QFD.

\subsection{Identificação do problema e objetivos da} pesquisa

A Ph.D. informática deseja lançar no mercado um software gerenciador de custos, dirigido a empresas de médio porte. O problema se resume em identificar junto aos clientes em potencial quais as características desejadas para este software.

Atualmente as softwareshouses da região não oferecem soluções avançadas em sistemas de custeio. Existem softwares de custos no mercado, mas esses produtos apresentam uma estrutura rígida, que não se adapta às necessidade individuais dos gerentes que tomam as decisões. Além disso, eles não oferecem opções avançadas de análise dos dados com o uso de metodologias modernas.

O objetivo principal da pesquisa é identificar os itens de qualidade demandada considerados mais importantes, verificando as características e informações que o programa deverá conter para atender as necessidades dos clientes, definindo se novas tecnologias de custeio serão valorizadas, e verificando a importância do uso de novas tecnologias de informática.

\subsection{Método e técnicas de coleta de dados}

Como fonte de dados secundários foram utilizadas referências do SEBRAE / Câmara de Indústria e Comércio e informações obtidas junto à funcionários da própria empresa. Para a coleta dos dados primários, foram utilizados questionários aplicados a clientes já existentes e clientes em potencial.

De posse dos dados obtidos nas fontes secundárias, foi possível elaborar um questionário aberto e, em seguida, um questionário estruturado, os quais foram aplicado aos clientes existentes e clientes em potencial (fonte primária de informação). Os questionários foram aplicados pessoalmente pelos pesquisadores.

\subsection{Determinação da população da pesquisa,} tamanho de amostra e processo de amostragem

A amostra da pesquisa foi determinada utilizando critério de amostragem não-probabilística por conveniência, pois havia a necessidade de concluir-se o estudo no menor tempo possível, com o menor custo. Sendo assim, 
os elementos da amostragem foram selecionados dentro do grupo que pôde ser consultado mais rapidamente. Este grupo se constituiu de diretores, gerentes e demais pessoas envolvidas com a área de custos das empresas que foram acessadas. No total foram entrevistados 22 clientes de empresas que possuem sede na região de caxias do Sul.

\subsection{Elaboração dos questionários}

Inicialmente foi elaborado um questionário com questões abertas, submetido ao grupo de clientes. A partir das respostas do questionário aberto, foi possível elaborar a árvore da qualidade demandada que orientou a elaboração do questionário fechado.

\subsubsection{Questionário aberto}

O questionário aberto visa prover o pesquisador de maior conhecimento sobre o objeto de pesquisa. Na sua elaboração, teve-se o cuidado de incluir perguntas formuladas de maneira simples, direcionadas aos objetivos do projeto, sem ambigüidades e na linguagem dos entrevistados. O anexo I apresenta uma cópia do questionário aberto aplicado. Os principais resultados obtidos aparecem apresentados na seqüência. Vale mencionar que os resultados do questionário aberto superaram as expectativas da equipe técnica, revelando detalhes (ver a seguir) desconhecidos para a equipe. A listagem obtida junto aos clientes é mais completa e mais exigente do que o que poderia ser obtido internamente, através de um brainstorm, por exemplo.

Questão 4 - Informações de custos consideradas importantes para tomada de decisões.

Informação on-line

Banco de dados atualizado

Custo unitário dos produtos

Matérias-primas atualizadas

Velocidade e acuracidade das informações

Gasto

Despesas gerais

Participação da Mão-de-obra por produto

Indicadores chave com capacidade de abertura
Custos contábeis

Custo gerencial

CPV

Custo indireto

Custo fixo

Ponto de equilíbrio

Custo final do produto

Imobilizado

Valor unitário por cento de custo

Questão 5 - Características relevantes na aquisição de um software de custo

Facilidade de uso

Boa interface com outros sistemas

Treinamento

Fácil acesso operacional

Personalizável

Ferramentas de simulações

Velocidade de processamento

Flexibilidade de adaptação das mudanças

Acuracidade nas informações
Atualização on-line

Possibilidade de cálculos em UEP

Simulação de cenários

Análise de custos fixos e variáveis

Cálculo de custo da qualidade

Cálculo de custo das perdas

Preço

Facilidade de manutenção

Sistema de custos utilizados pelo software 
Questão 6-Quais as principais falhas nos softwares existentes no mercado e quais as melhorias que podem ser adicionadas.

Problemas de interface com outros sistemas

Rigidez na estrutura

Dificuldade de se ter relatórios novos

Falta de apresentações gráficas

Apropriações grotescas

Demora no cálculo

Dificuldade de parametrização

Dificuldade de aquisição dos dados

Sistemas complexos que resultam na utilização deficiente de custos
Falta de simulação de cenários

Não utilização da UEP

Dados não utilizáveis

Utilização de base contábil

Não tem visão processo

Falta de informação globais

Não são didáticos

Informações incompletas

Menus não padronizados

Questão 7 - Características que levam a aquisição de um software de custo

Custo de aquisição e manutenção

Disponibilidade de recursos do sistema

Facilidade de utilização

Atendimento rápido ao cliente

Rapidez de resposta

Interatividade

Precisão

Questão 8 - Forma de divulgação mais eficiente

Demonstração na empresa

Workshop

Divulgação pessoal

\subsection{2. Árvore da Qualidade demandada}

Após a análise dos itens de qualidade demandada, foi possível organizá-los em níveis primário, secundário e terciário, conforme apresentado na tabela 1 .

\subsubsection{Questionário Fechado}

O questionário fechado é composto de questões com alternativas que são os itens da árvore de qualidade demandada. O objetivo deste questionário é obter a priorização desses itens. O questionário fechado também contemplou alguns poucos itens de interesse direto da empresa para serem avaliados pelos clientes. Este questionário encontra-se no Anexo II.

\author{
Manual com exemplos e exercícios \\ Tela menos poluída \\ Linguagem de fácil compreensão \\ Menus adequados \\ Cores agradáveis \\ Help sensível ao contexto \\ Integração com internet
}

\subsubsection{Tabulação dos dados do questionário fechado}

O desdobramento da demanda da qualidade até o nível terciário foi importante para conhecer detalhes das expectativas do cliente. Estes detalhes estão sendo amplamente utilizados nas decisões referentes a concepção do produto e dos recursos que ele deve possuir.

No entanto, o excessivo detalhamento do nível terciário impediu que ele fosse utilizado como ponto de partida para a elaboração da matriz da qualidade. No nível terciário existe um número muito grande de itens, o que iria gerar matrizes muito extensas. Além disso, não é possivel identificar características de qualidade associadas a todos os itens. 
Tabela 1: Árvore da Qualidade Demandada para o estudo de caso do Software de Custo

\begin{tabular}{|c|c|c|}
\hline Primário & Secundário & Terciários \\
\hline \multirow[t]{3}{*}{$\begin{array}{l}\text { Técnicas } \\
\text { Atualizadas }\end{array}$} & $\begin{array}{l}\text { Interface } \\
\text { (Entrada e Saída ) }\end{array}$ & $\begin{array}{l}\text { Fácil de usar } \\
\text { Menus padronizados } \\
\text { Acesso fácil às informações } \\
\text { Interface com outros sistemas } \\
\text { Personalizável às necessidades } \\
\text { Interface gráfica } \\
\text { Facilidade de navegação } \\
\text { Leve e limpo } \\
\text { Relatório de fácil leitura }\end{array}$ \\
\hline & Boa Performance & $\begin{array}{l}\text { Confiabilidade } \\
\text { Velocidade } \\
\text { Eficiência da resposta } \\
\text { Flexibilidade de adequação às mudanças }\end{array}$ \\
\hline & Novas Tecnologias & $\begin{array}{l}\text { Integração com internet } \\
\text { Reconhecimento de voz } \\
\text { Capacidade de rodar em computadores portáteis }\end{array}$ \\
\hline \multirow{2}{*}{ Métodos Eficazes } & Métodos de Análise & $\begin{array}{l}\text { Personalização } \\
\text { Simulação de cenários } \\
\text { Ponto de equilibrio } \\
\text { Informações globais } \\
\text { Informações detalhadas }\end{array}$ \\
\hline & Métodos de Custeio & $\begin{array}{l}\text { Custo contábil } \\
\text { Custo gerencial } \\
\text { Custo produto vendido } \\
\text { UEP } \\
\text { ABC } \\
\text { Custo Padrão } \\
\text { Custo da qualidade } \\
\text { Custo das perdas } \\
\text { Custo da melhoria do processo }\end{array}$ \\
\hline \multirow[t]{2}{*}{$\begin{array}{l}\text { Serviços } \\
\text { Eficientes }\end{array}$} & $\begin{array}{l}\text { Boa estrutura de } \\
\text { Manutenção / Suporte }\end{array}$ & $\begin{array}{l}\text { Suporte acessível } \\
\text { Treinamento } \\
\text { Adequação à novas demandas } \\
\text { Facilidade autoaprendizado } \\
\text { Atendimento rápido } \\
\text { Manual com exemplos e exercícios }\end{array}$ \\
\hline & Personalização no serviço & $\begin{array}{l}\text { Indicadores chave com capacidade de abertura } \\
\text { Flexibilidade na estrutura } \\
\text { Personalizável pelo usuário }\end{array}$ \\
\hline \multirow[t]{3}{*}{$\begin{array}{l}\text { Informações } \\
\text { Confiáveis }\end{array}$} & Segurança dos dados & $\begin{array}{l}\text { Restrição ao acesso (senhas) } \\
\text { Back-up on-line } \\
\text { Segurança da não perda de dados na queda do sistema } \\
\text { Segurança contra vírus }\end{array}$ \\
\hline & $\begin{array}{l}\text { Confiabilidade das } \\
\text { informações }\end{array}$ & $\begin{array}{l}\text { Informações precisas } \\
\text { Acuracidade } \\
\text { Detecção de erros }\end{array}$ \\
\hline & $\begin{array}{l}\text { Atualização em tempo } \\
\text { real }\end{array}$ & $\begin{array}{l}\text { Informações on-line } \\
\text { Banco de dados atualizado }\end{array}$ \\
\hline
\end{tabular}


Assim, optou-se por utilizar o nível secundário como informação de entrada na matriz da qualidade. $\mathrm{O}$ nível secundário apresenta-se suficientemente detalhado e apropriado ao objetivo do trabalho. Os resultados da avaliação da importância do nível secundário, conforme atribuída pelos clientes que responderam ao questionário fechado, aparecem na Matriz da Qualidade (Tabela 2).

\section{4 - Matriz da Qualidade}

Para a construção da Matriz da Qualidade foram utilizados os itens secundários da qualidade demandada, conforme apresentado na seção anterior. Além disso, também foram definidas as características de qualidade e seus respectivos critérios de mensuração:

- Tempo de aprendizado (dias) - é o tempo necessário de treinamento para que o usuário possa utilizar $80 \%$ dos recursos do software. Quando o usuário atinge o nível de $80 \%$, considera-se que ele já detém o domínio (aprendizado) do software.

- Tempo médio p/ entrada de dados (minutos) - É o tempo médio que o usuário leva para completar uma transação sem erros.

- Número de erros não detectados automaticamente (qtde. de erros / mês) - Será considerado erros não detectados todo o erro que não é detectado automaticamente pelo sistema, sendo detectado somente nos procedimento de conferência efetuados pelo usuário.

- Número de atendimentos ao usuário (qtde. / mês) É a quantidade de atendimentos ao usuário seja por telefone, pessoalmente, via e-mail ou qualquer outro meio.

- Benchmarking com outros sistemas de custeio (qtde. itens atendidos) - Baseado em artigos especializados na área que citam as principais características dos sistemas de custeio, foi feita uma lista de características que serão ou não atendidas pelo sistema. Esta lista deverá ser atualizada anualmente para manter a atualização tecnológica: documentação On-line; Tutorial passo a passo; Modelos de exemplo prontos; Multi- usuário; Client/Server; Web-based; Suporte a tecnologia 3-tier; Uso de interface gráfica; Integração com planilhas eletrônicas; Relatórios customizados; Análise dos dados graficamente; Suporte a várias moedas; Metodologia de custeio suportada (ABC ;UEP, Centro de Custos, etc.); Suporte a ABM; Formação de preço; Análise de capacidade; Análise de rentabilidade (por Área de negócio, Segmento, Cliente, Produto,Canal de venda, etc.); Análise What-if; Suporte à reengenharia de processos; Análise dos dados em formato de cubo; Suporte à consistência de dados complexos.

-Quantidade de horas de treinamento (horas) - É um indicador do tipo menor é melhor. O sistema deve ser auto-explicativo e não devem ser necessárias muitas horas de treinamento para a sua operação.

-Quantidade de horas p/ customização (horas) - É um indicador do tipo menor é melhor. O sistema deve ser flexível para se adequar a diferentes cenários, sem a necessidade de muitas horas de customização.

- Tempo médio p/atendimento aos chamados (horas) - Todo o chamado demanda um tempo para ser atendido, este indicador controla a quantidades de horas média para estes atendimentos.

- Defasagem de atualização do sistema (dias) Como o sistema de custos é um sistema gerencial, e não operacional ou legalmente obrigatório, o usuário utiliza-se dele se o mesmo for útil; se o sistema não está atualizado ou seja defasado é sinal que o mesmo não está sendo utilizado eficientemente.

O grupo encarregado da elaboração do QFD pontuou o inter-relacionamento entre os itens da qualidade demandada e as características de qualidade. Foi utilizada a seguinte escala: Muito Forte - 9; Forte - 5; Médio - 3; Fraco - 1; Nenhum - 0.

Na priorização da demanda de qualidade também foram considerados os aspectos estratégicos (quanto que uma determinada demanda deve crescer em importância no futuro) e competitivo (quanto estamos defasados de nossos concorrentes). Como pode ser visto na Figura 2, os itens mais importantes são a confiabilidade das informações e os métodos de custeio utilizado. 
Tabela 2: Matriz da Qualidade para o estudo de caso do software de custo.

\section{Matriz da Qualidade}

tterface de fácil cesso

'erformance do istema

Método de custeio

গanutenção e uporte adequado

'ersonalização itualização em эmpo real ;onfiabilidade das Iformações Iso de novas zcnologias iegurança de dados - acesso 1étodo de análise vançado

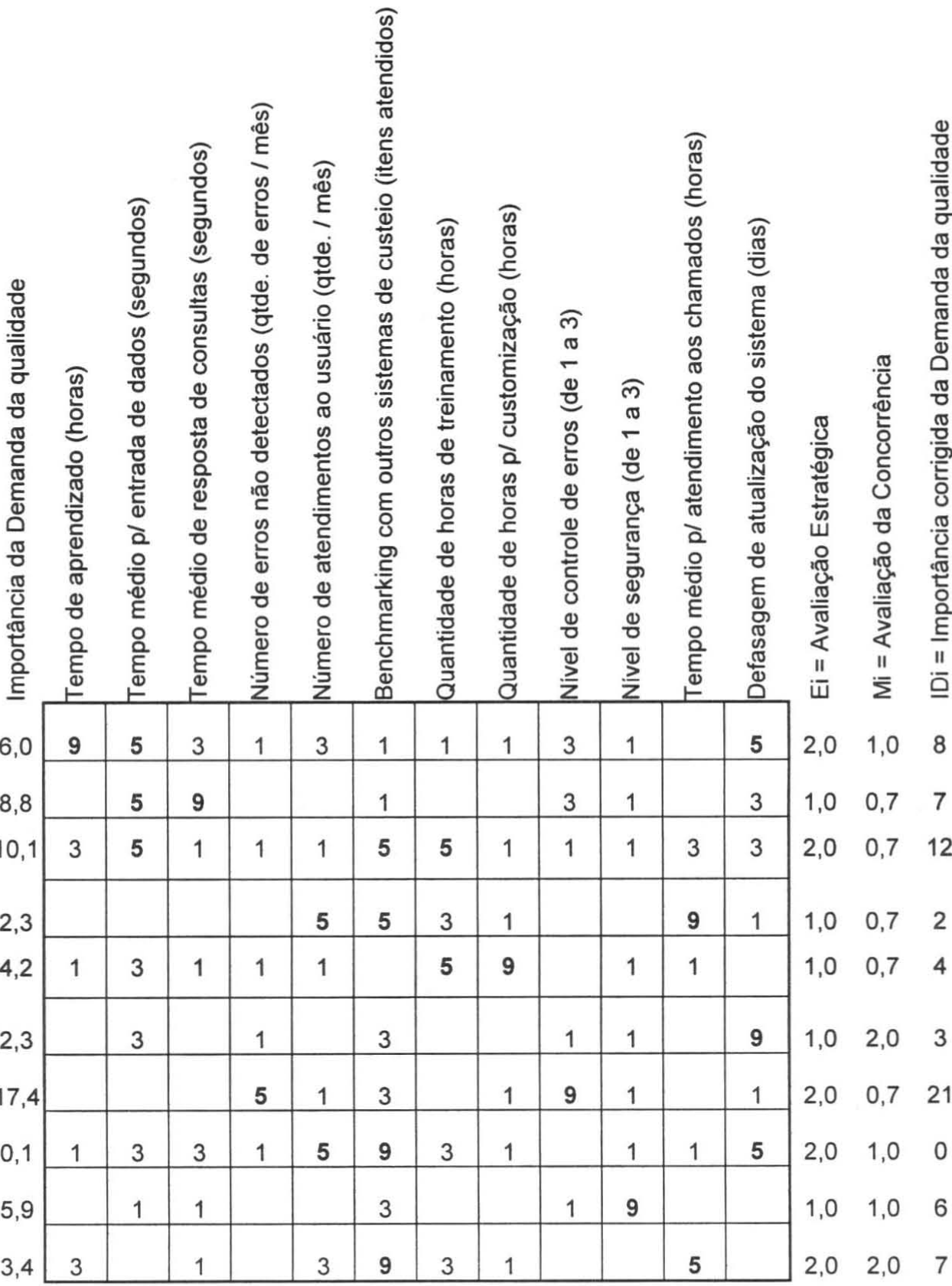

Especificações

Importância: IQj $\quad \begin{array}{llllllllllll}1,4 & 1,7 & 1,2 & 1,3 & 0,9 & 2,4 & 1,1 & 0,8 & 2,5 & 1,1 & 0,9 & 1,5\end{array}$

Análise competitiva

Dificuldade de atuação

nportância corrigida:

IQj*

$$
\begin{array}{llllllllllll}
1,5 & 1,0 & 0,7 & 0,5 & 1,0 & 0,7 & 1,0 & 1,0 & 0,7 & 1,0 & 0,7 & 1,0 \\
1,5 & 1,5 & 1,0 & 1,5 & 0,5 & 0,7 & 0,5 & 0,7 & 1,5 & 1,5 & 0,7 & 1,5 \\
2,0 & 2,0 & 1,0 & 1,1 & 0,7 & 1,7 & 0,8 & 0,7 & 2,6 & 1,3 & 0,6 & 1,9
\end{array}
$$


PRODUÇÃO

$\mathrm{Na}$ priorização das características de qualidade também foram avaliados a posição da empresa frente aos principais concorrentes e a dificuldade de atuação (dificuldade de alterar as especificações de determinada característica de qualidade). Os resultados apontaram como características de qualidade mais importantes $o$ nivel de controle de erro e o tempo de aprendizado.

\section{5 - Matriz das Partes}

A Matriz das Partes ou Matriz do produto, no caso de um software, contém todos os módulos que o constituem. Essa matriz foi elaborada a partir do grau de relacionamento entre as partes e as características de qualidade, conforme apresentado na Tabela 3.

\section{Confiabilidade das informações Método de custeio Interface de fácil acesso \\ Performance do sistema Método de análise avançado Segurança de dados e acesso \\ Personalização Atualização em tempo real Manutenção e suporte adequado Uso de novas tecnologias}

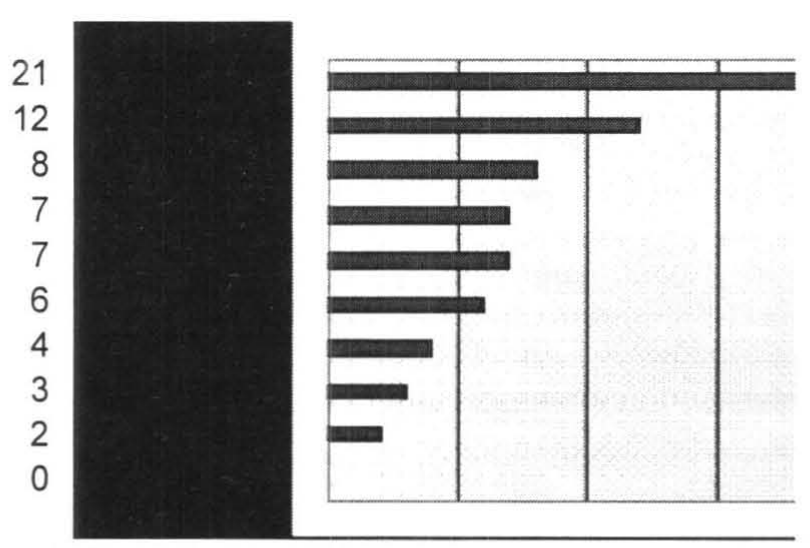

Figura 2: Priorização dos itens de demanda da qualidade.

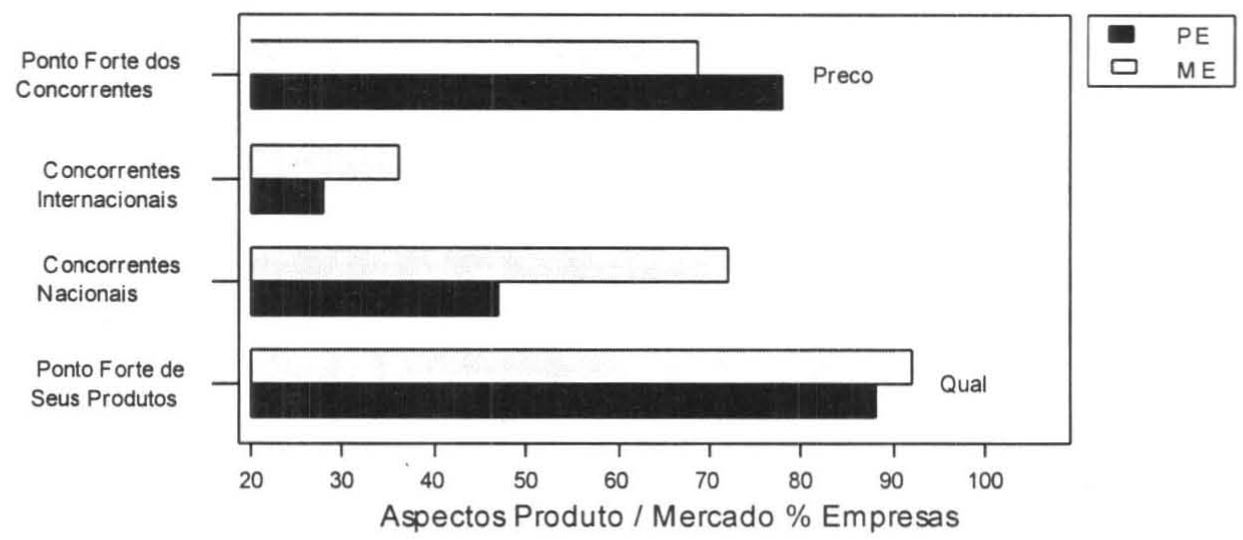

Figura 3 - Aspectos de Produto / Mercado das Empresas 
Tabela 3: Matriz das partes para o estudo de caso do software de custo.

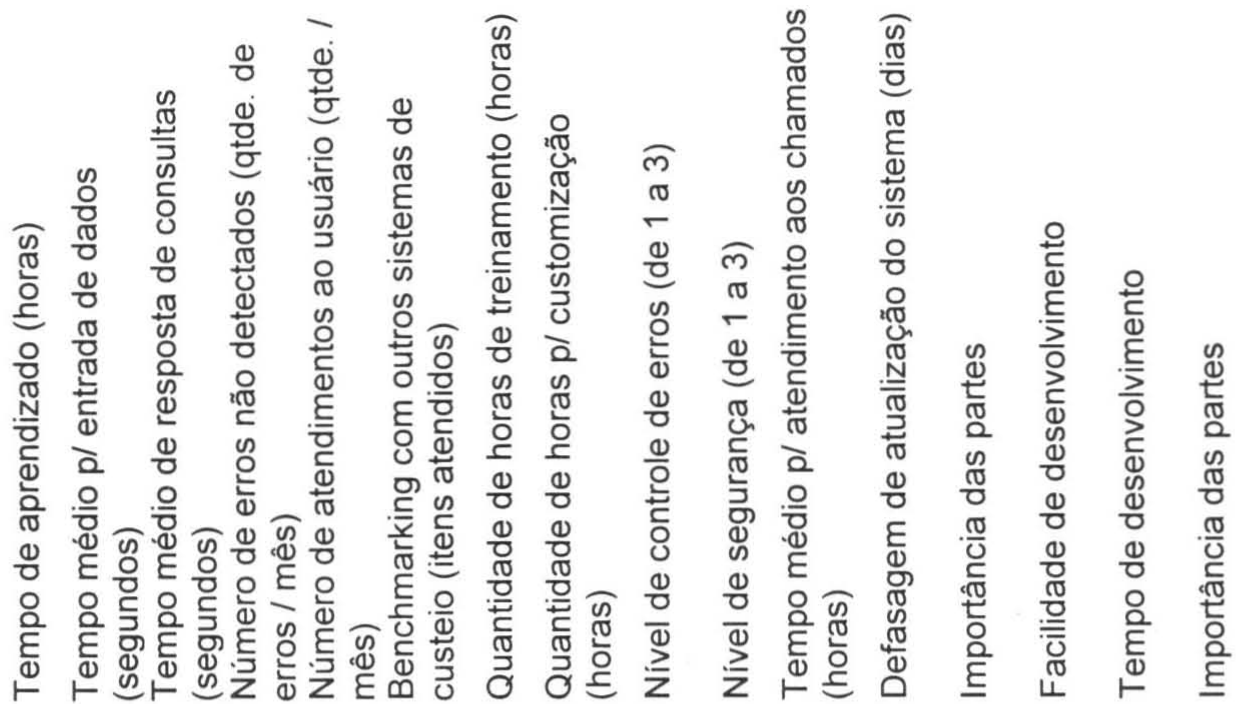

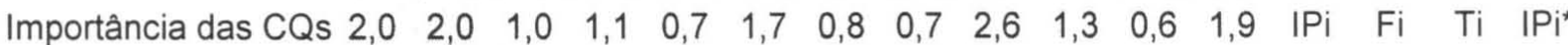

\begin{tabular}{|c|c|c|c|c|c|c|c|c|c|c|c|c|c|c|c|c|}
\hline Modulo de Cálculos & & & 3 & 3 & 1 & 9 & & & 3 & & & & 3,0 & 2,0 & 0,7 & 3,6 \\
\hline $\begin{array}{l}\text { Modulo de Consulta } \\
\text { Gerenciais }\end{array}$ & 5 & & 9 & & 3 & 5 & 5 & 3 & & 1 & 3 & & 3,9 & 1,5 & 0,7 & 4,0 \\
\hline $\begin{array}{l}\text { Modulo de Entrada } \\
\text { de Dados }\end{array}$ & 5 & 9 & 1 & 5 & 5 & 1 & 3 & 3 & 5 & 5 & 3 & 3 & 7,1 & 0,5 & 1,0 & 5,0 \\
\hline Modulo Help & 9 & 1 & & & 5 & & 3 & & & & & & 2,6 & 0,5 & 1,0 & 1,8 \\
\hline $\begin{array}{l}\text { Modulo de Criação de } \\
\text { Cenários }\end{array}$ & 5 & 5 & 5 & 1 & 3 & 9 & 5 & 1 & 1 & 1 & 1 & & 5,3 & 2,0 & 0,5 & 5,3 \\
\hline Modulo de Cadastros & 9 & 1 & 1 & 5 & 3 & & 5 & 3 & 5 & 5 & 3 & 3 & 6,2 & 0,5 & 1,0 & 4,4 \\
\hline $\begin{array}{l}\text { Modulo de } \\
\text { Verificação de Erros }\end{array}$ & & 3 & & 9 & 3 & 3 & & & 9 & & & 1 & 4,8 & 2,0 & 0,5 & 4,8 \\
\hline Modulo de Segurança & & 1 & 1 & & & 3 & & & & 9 & & & 2,0 & 1,0 & 1,0 & 2,0 \\
\hline $\begin{array}{l}\text { Modulo de Interface } \\
\text { com outros sistemas }\end{array}$ & 3 & 5 & & 5 & 1 & 3 & 1 & 5 & 5 & 3 & 1 & 9 & 6,6 & 1,5 & 1,5 & 9,9 \\
\hline $\begin{array}{l}\text { Modulo de personaliz. } \\
\text { de Consultas }\end{array}$ & 5 & & 9 & & 5 & 3 & 5 & 5 & & 1 & 1 & & 3,7 & 2,0 & 0,7 & 4,4 \\
\hline
\end{tabular}

$\begin{array}{rr}\text { Modulo de Interface com outros sistemas } & 9,9 \\ \text { Modulo de Criação de Cenários } & 5,3 \\ \text { Modulo de Entrada de Dados } & 5,0 \\ \text { Modulo de Verificação de Erros } & 4,8 \\ \text { Modulo de Cadastros } & 4,4 \\ \text { Modulo de Personalização de Consultas } & 4,4 \\ \text { Modulo de Consulta Gerenciais } & 4,0 \\ \text { Modulo de Cálculos } & 3,6 \\ \text { Modulo de Segurança } & 2,0 \\ \text { Modulo Help } & 1,8\end{array}$

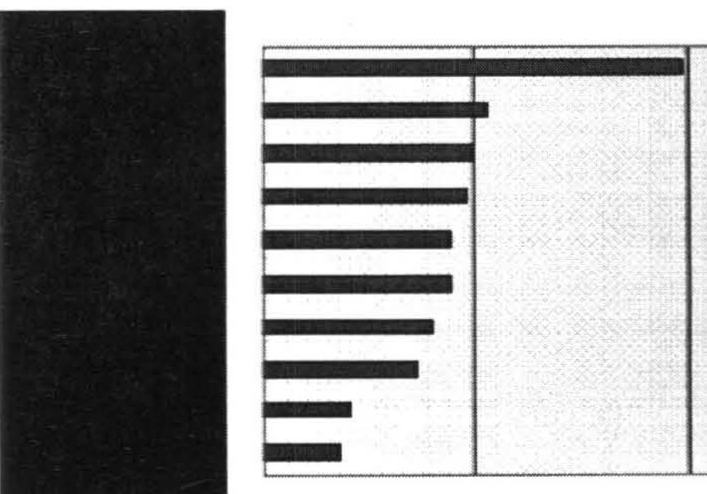

Figura 4: Priorização das Partes do produto. 
PRODUÇÃO

Na priorização das partes também foram considerados os aspectos relativos à facilidade e tempo necessário ao desenvolvimento de cada módulo. A priorização das partes aparece ilustrada na Figura 4. Como pode ser visto na Figura 4, as partes prioritárias são o módulo de interface com outros sistemas e o módulo de criação de cenários.

\section{6 - Matriz das Características das Partes}

Nesta matriz são estabelecidas a intensidade dos relacionamentos entre as partes e as características de qualidade. A seguir são apresentados os indicadores utilizados para a classificação das características de qualidade das partes do produto.

- Nivel de controle de erros (de 1 a 3 ) - será considerado nível 0 (zero) o sistema sem controle de erro, 1 com controle de erros básicos a nível de aplicação, 2 com controle de erros básicos a nível da aplicação e servidor, 3 métodos complexos de análise de dados para detectar erros.

- Nível de segurança (de 1 a 3 ) - 0 sem nenhum tipo de segurança, 1 - segurança a nível de senhas, 2 segurança anterior e encriptografia dos arquivos, 3 segurança anterior e encriptografia da comunicação

- Tempo de resposta (segundos) é o intervalo de tempo entre o início de um método até o término do mesmo. Na programação dos métodos será colocado linhas de código que gravarão o tempo de resposta de cada método de forma individual e acumulada.

- Número de consultas realizadas (Quantidade) o sistema manterá uma estatística de número de consultas realizadas pelos usuários com seu nome, data, hora e tipo de consulta. Quanto maior for a quantidade de consultas feitas, mais útil é a consulta.

- Nível de detalhamento (Quantidade de níveis) é a quantidade de detalhamento que as consultas suportam, por exemplo se temos uma consulta que nos informa $o$ total faturado no ano e se nós quisermos o mesmo por meses e depois por dia teremos uma consulta de 3 níveis.

- Quantidade de dimensões suportada (Quantidade de dimensões) as consultas são montadas em forma de cubo ou seja podemos ver as vendas por período, ou por região, ou ainda por vendedor, ou produto neste caso temos 4 dimensões.

-Quantidade de Métodos de Custeio Suportados (Quantidade) é a quantidade de métodos suportados capazes de transformar as mesmas entradas em saidas através de métodos algoritmos diferenciados para propiciar a comparação dos resultados.

- Tempo de carga dos dados (segundos) é o tempo de resposta da importação dos dados de outros sistemas.

-Quantidade de sistemas suportados nativamente (Número de sistemas), é o número de sistemas de terceiros que são suportados pelo sistema de forma on-line.

-Número de comandos suportados (Quantidade de comandos) é a quantidade de recursos disponíveis para o usuário desenvolver o seu trabalho.

-Quantidade de Exemplos e exercícios (Quantidade) - é o número de tutoriais com exemplos e exercícios disponíveis ao usuário.

-Quantidade de métodos suportados na simulação (Quantidade) - é a quantidade de algoritmos de simulação suportados pelo sistema

A Matriz das caracteristicas das partes aparece na Tabela 4 e a priorização das características das partes está apresentada na Figura 5. A análise da Figura 5 revela que os indicadores mais importantes são o tempo de resposta, o tempo de aprendizado e o tempo de preenchimento. 
Tabela 4: Matriz das características das partes para o estudo de caso do software de custo.

itriz das

racterísticas das rtes

idulo de Cálculos idulo de Consulta renciais

ıdulo de Entrada de dos

idulo Help

ıdulo de Criação de nários

idulo de Cadastros ıdulo de Verificação Erros

idulo de Segurança idulo de Interface $n$ outros sistemas idulo de Personaliz. Consultas

mportância das CPs

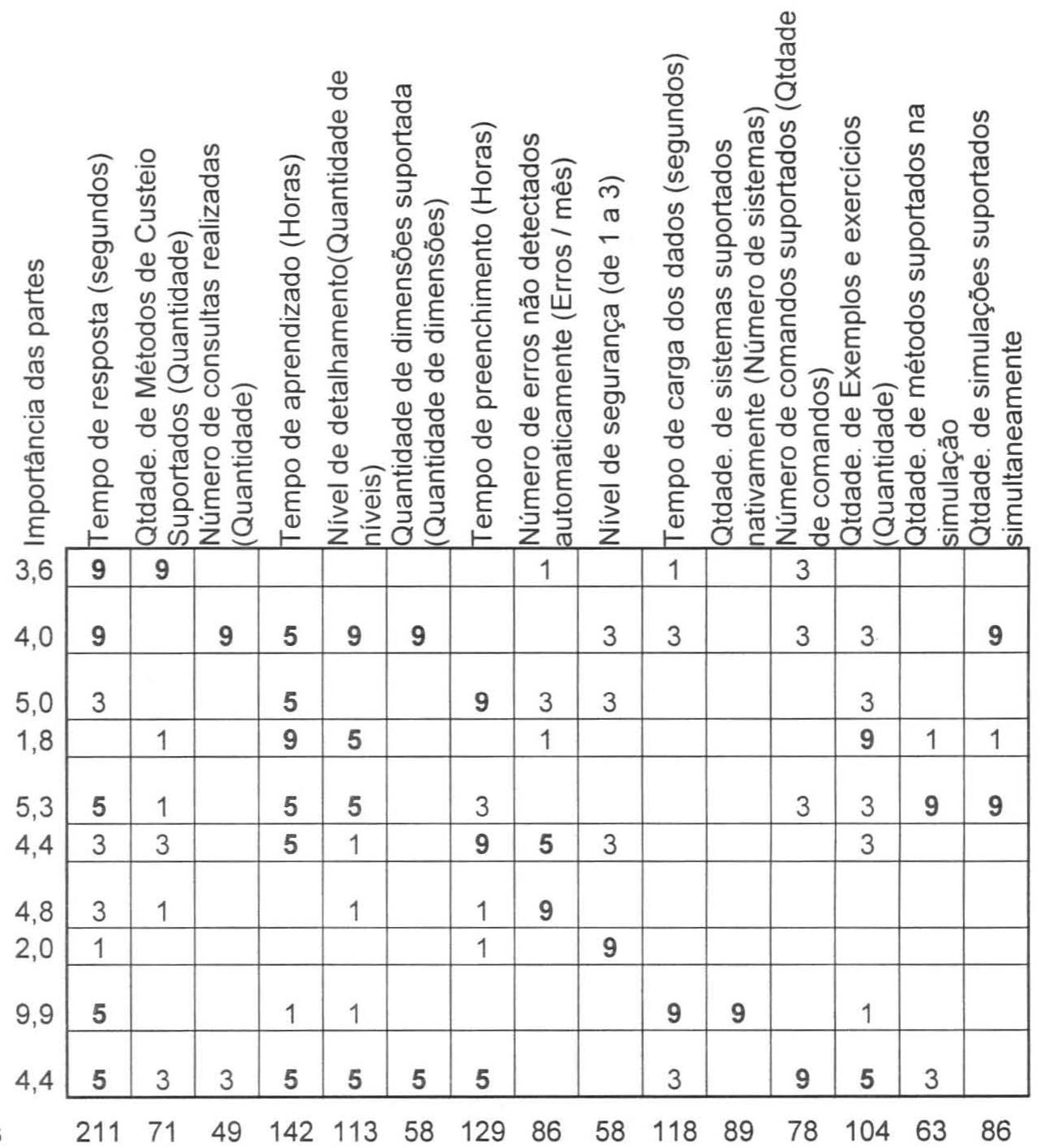




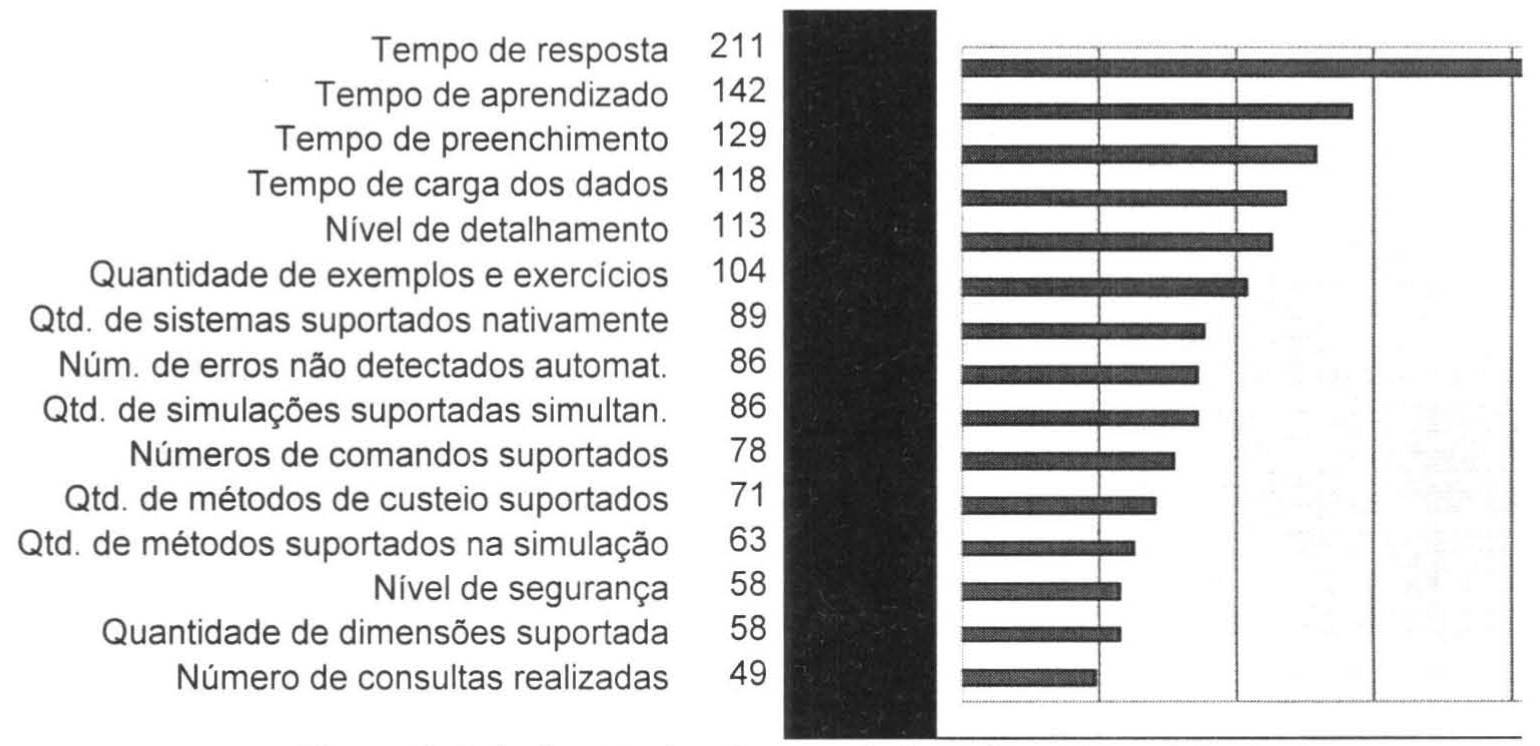

Figura 5: Priorização das Características das partes.

\section{7 - Matriz dos Processos}

Como o produto em estudo - software - efetivamente envolve considerações relativas a produto e serviço, a matriz de processos (ver Tabela 5), neste estudo de caso, incorpora tanto os processos de fabricação (desenvolvimento de software) como os processos de prestação de serviços da empresa.

A Figura 6 evidencia que as duas etapas inicias do desenvolvimento do software (análise de atributos do sistema e projeto do produto) devem ser priorizadas. Este fato coincide com a prática defendida pela maioria dos autores de engenharia de software, que pregam que um esforço maior deve ser feito nas fases inicias de desenvolvimento, evitando retrabalhos futuros.

O treinamento também é um dos itens destacados. Isso realça a importância crescente que vem sendo atribuída a capacitação de funcionários, fato este que nem sempre é priorizados pelos desenvolvedores de software.

\section{8 - Matriz dos Parâmetros dos Processos}

Na área de desenvolvimento de softwares um dos problemas associados é a falta de controle durante o processo. Neste sentido, estabelecer os parâmetros para controle dos processo é fundamental para o sucesso das atividades de desenvolvimento e assessoria.

Visando o preenchimento da matriz dos parâmetros dos processos, foram identificados os seguintes indicadores (parâmetros do processo):

- Pontos perdidos nas revisões (pontos) - em todas as fases do ciclo de vida do software, após o termino de uma tarefa, a mesma é submetida a uma equipe técnica que aponta erros e ou melhorias a serem feitas. Conforme o grau de impacto do erro no resto do sistema a tarefa perde mais pontos ou menos. Por exemplo, se um erro de análise é detectado na fase de programação o custo para se consertar o mesmo é maior do que se fosse descoberto na fase de análise propriamente dita.

- Método do ponto de função (pontos) - é um método de engenharia de software para calcular quão complexo é um módulo baseado nas informações de entrada e saída que o mesmo deve gerar. Quanto maior for a pontuação mais complexo é o módulo e mais tempo será necessário para programá-lo. O objetivo é ter módulos simples objetivando a fácil manutenibilidade e entendimento do sistema. 
-Complexidade ciclomática (grau) - é um método de engenharia de software para calcular quão complexo é um módulo baseado no número de laços que tem um programa. Este método é mais utilizado em módulos com programação mais complexa.

- Tempo manutenção x desenvolvimento (\%) - é o percentual de tempo em que estão envolvidas as pessoas corrigindo erros e fazendo manutenções no software em relação ao tempo total que será computado como tempo de manutenção + tempo de desenvolvimento de novos módulos.

- Tempo médio de implantação do software (dias) será considerado o tempo entre o início da implantação do sistema até o termino da implantação do mesmo, ou seja quando o cliente começa a utilizar o sistema regularmente.
- Questionário de avaliação do instrutor (nota) - será criado um questionário com várias questões pontuadas de 1 a 10 , permitindo que a média das notas dos alunos será computada.

-Questionário de avaliação do assessor (nota) - será criado um questionário com várias questões pontuadas de 1 a 10 , permitindo que a média das notas da diretoria será computada.

-\% de consultas com êxito ao help (\%) - é a quantidade de consultas que ajudaram na solução do problema do usuário feitas ao help sobre o total de consultas, o sistema após cada consulta solicitará ao usuário se o mesmo teve sua dúvida resolvida.

A Tabela 6 apresenta a matriz dos parâmetros do processo e a Figura 7 revela que os parâmetros mais

Tabela 5: Matriz dos processos para o estudo de caso do software de custo.

Matriz dos Processos

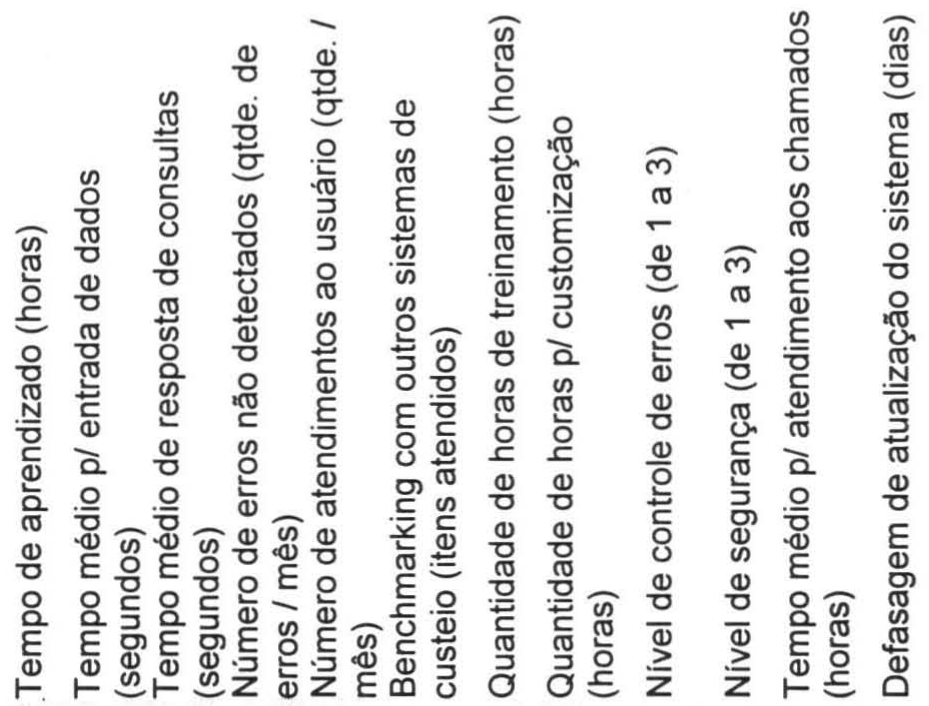

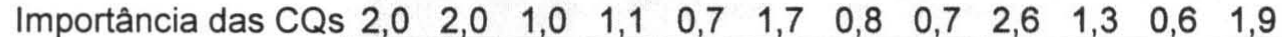

Análise dos atributos
Projeto do produto
Desenvolvimento
Documentação
Assessoria p/ implant.
Treinamento
Suporte / Manutenção

\begin{tabular}{|l|l|l|l|l|l|l|l|l|l|l|l|}
\hline $\mathbf{9}$ & 3 & 3 & $\mathbf{5}$ & 1 & $\mathbf{9}$ & 1 & $\mathbf{5}$ & $\mathbf{5}$ & $\mathbf{5}$ & & 3 \\
\hline $\mathbf{5}$ & $\mathbf{5}$ & $\mathbf{5}$ & 3 & 1 & 3 & 3 & 3 & 3 & 3 & & 3 \\
\hline 3 & $\mathbf{9}$ & $\mathbf{9}$ & $\mathbf{5}$ & 1 & 1 & 1 & $\mathbf{5}$ & $\mathbf{5}$ & $\mathbf{5}$ & & 3 \\
\hline $\mathbf{9}$ & & & 1 & $\mathbf{5}$ & & $\mathbf{5}$ & 1 & & & 1 & \\
\hline $\mathbf{5}$ & & & 1 & 3 & 3 & 1 & $\mathbf{5}$ & 1 & & & \\
\hline $\mathbf{9}$ & 3 & & 3 & $\mathbf{5}$ & 3 & $\mathbf{9}$ & 1 & 1 & & & 1 \\
\hline & & & & $\mathbf{9}$ & 3 & 1 & & 3 & & $\mathbf{9}$ & \\
\hline
\end{tabular}

$\begin{array}{lllll}0,8 & 0,5 & 1,0 & 0,6\end{array}$

$\begin{array}{llll}0,6 & 1,5 & 1,5 & 0,8\end{array}$

$\begin{array}{llll}0,7 & 1,0 & 0,5 & 0,5\end{array}$

$\begin{array}{llll}0,3 & 2,0 & 1,5 & 0,5\end{array}$

$\begin{array}{llll}0,3 & 1,5 & 2,0 & 0,4\end{array}$

$\begin{array}{llll}0,5 & 1,5 & 2,0 & 0,8\end{array}$

$\begin{array}{llll}0,3 & 1,5 & 2 & 0,4\end{array}$ 


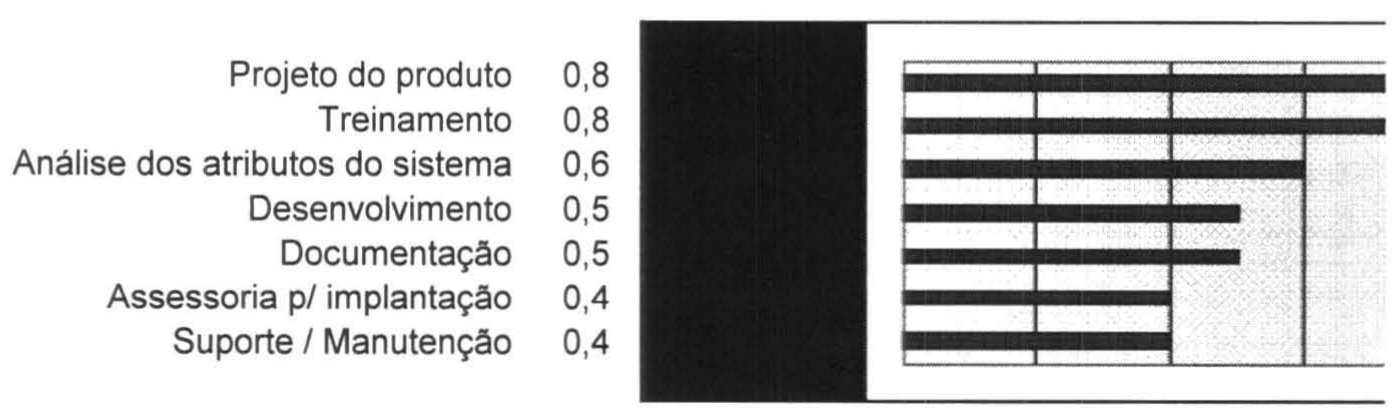

Figura 6: Priorização dos processos

importantes são os pontos perdidos na revisão, o questionário do assessor e o tempo médio de implantação do software.

\section{9 - Matriz dos recursos humanos e recursos de} infraestrutura

A tabela 7 apresenta os itens referentes a recursos humanos e itens referentes a infra-estrutura, relacionando os mesmos aos processos e serviços necessários para o desenvolvimento e manutenção do produto. Assim, é possível relacionar de forma indireta as características de qualidade aos recursos humanos e a infra-estruturas necessárias a sua realização. Como pode ser visto na Figura 8, os itens de RH mais importantes são os analistas e o assessor de custos. Ao mesmo tempo, a Figura 9 indica que os itens de infraestrutura prioritários são os computadores, impressoras e ferramentas de análise (softwares especializados).

\section{0 - Matriz dos custos}

A matriz dos Custos (ver tabela 8) avalia o custo dos processos de desenvolvimento e manutenção do software. Ela permite verificar se a alocação de custos é proporcional a importância dos diversos processos.

Como pode ser visto na Figura 10, o processo que mobiliza mais recursos é desenvolvimento do produto. Isso evidencia ainda mais a importância das fases anteriores - Análise dos atributos do sistema e Projeto do produto. Erros nessas fases implicam em grande retrabalho na etapa de desenvolvimento, que é a etapa mais cara.

\section{1 - Plano da melhoria da qualidade}

O plano de melhoria da qualidade é a última etapa do QFD e permite fazer a transição necessária para o desenvolvimento de um produto com qualidade superior. Este planejamento é feito a partir dos resultados de todas as matrizes anteriores. Os itens priorizados em cada etapa são contemplados no plano de melhorias. Como as matrizes são interrelacionadas, o plano final é constituído de uma série de ações integradas, definidas a partir de um mesmo alinhamento: a satisfação das necessidades do cliente. Um resumo do planejamento da qualidade aparece na tabela 9 . 
Tabela 6: Matriz dos parâmetros do processo para o estudo de caso do software de custo.

\section{Matriz dos Parâmetros do processo}

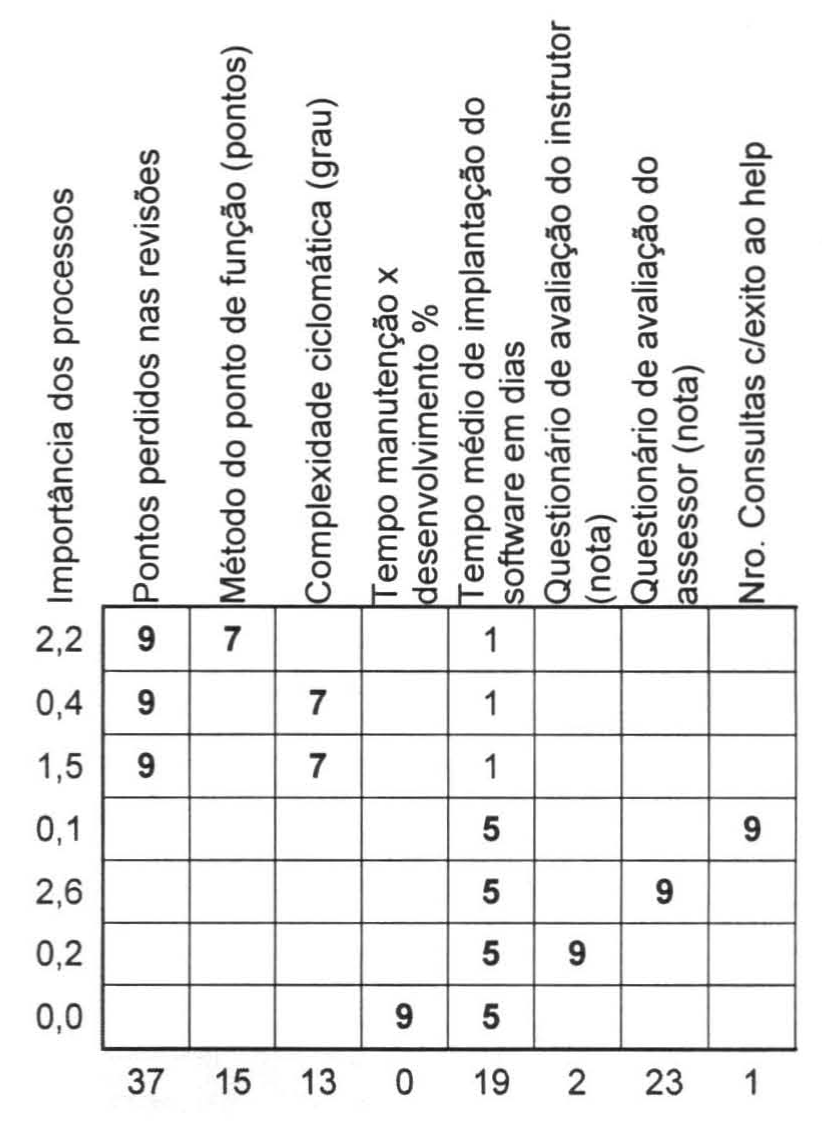

Análise

Projeto

Desenvolvimento

Documentação

Assessoria p/ implantação

Treinamento

Suporte / Manutenção

Importância dos parâmetros

Pontos perdidos nas revisões Questionário de avaliação do assessor Tempo médio de implantação do software Método do ponto de função Complexidade ciclomática Questionário de avaliação do instrutor Nro. Consultas c/exito ao help Tempo manutenção $x$ desenvolvimento

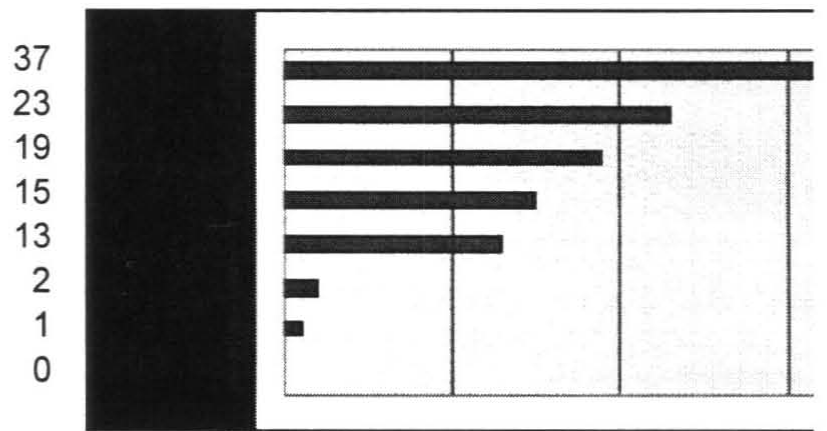

Figura 7: Priorização dos parâmetros do processo 
Tabela 7: Matriz dos recursos para o estudo de caso do software de custo.

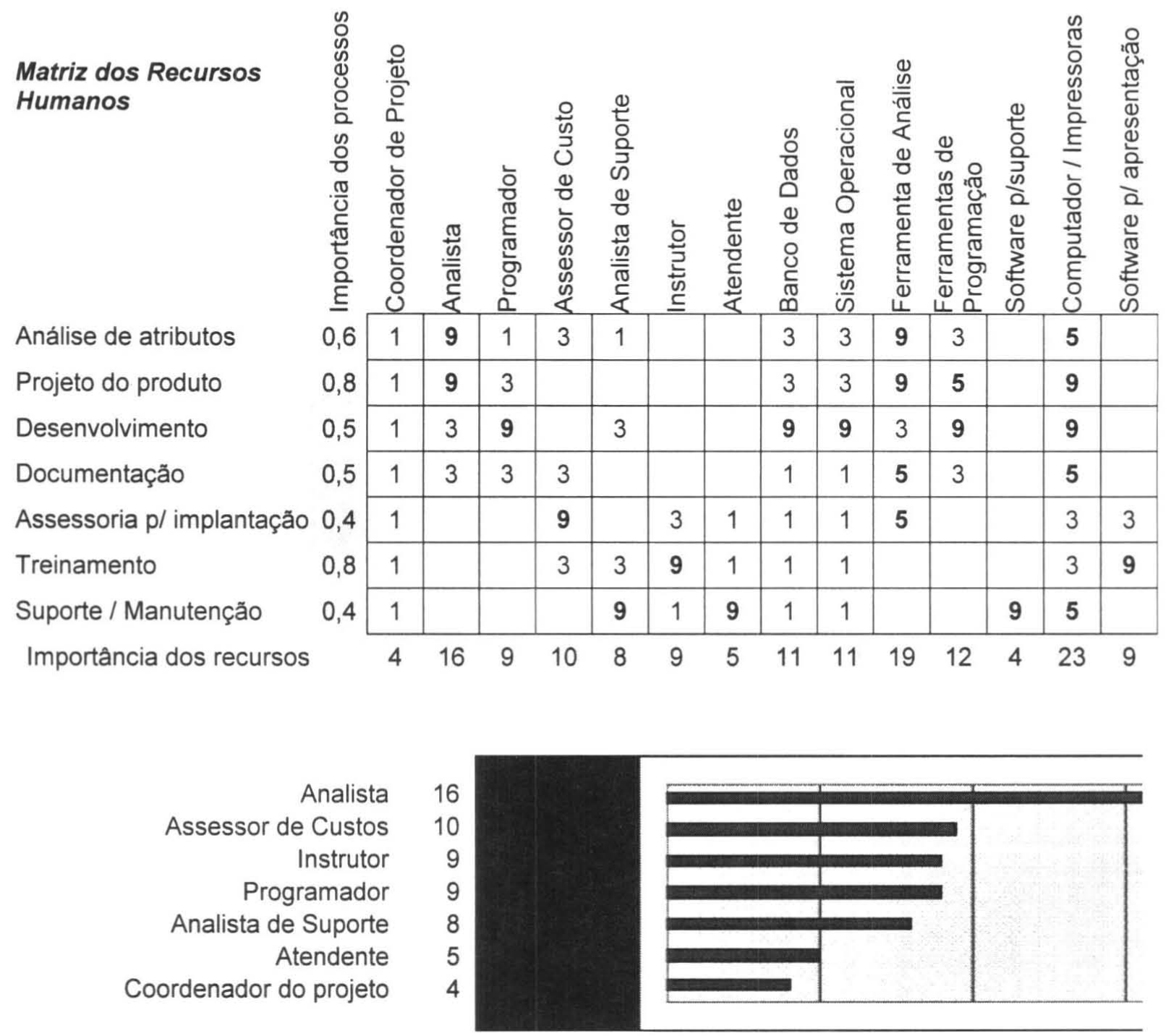

Figura 8: Priorização dos Recursos Humanos

\section{Computador / Impressoras \\ Ferramentas de análise \\ Ferramentas de programação \\ Sistema operacional \\ Banco de dados \\ Software p/ apresentação \\ Software $p /$ suporte}

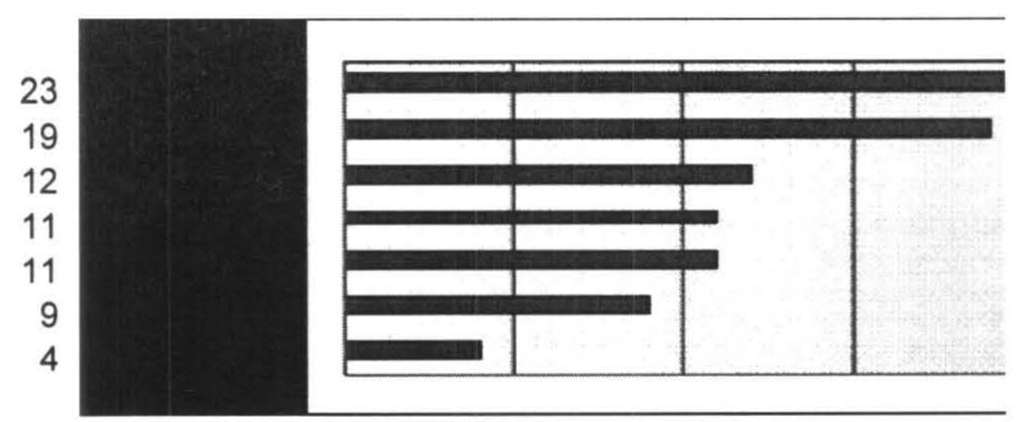

Figura 9: Priorização da Infra Estrutura 
Tabela 8: Matriz dos Custos para o estudo de caso.

Matriz dos Custos

Análise de atributos

Projeto do produto

Desenvolvimento

Documentação

Assessoria p/ implantação

Treinamento

Suporte / Manutenção

\begin{tabular}{|c|c|c|c|c|c|c|c|c|c|c|c|c|c|c|}
\hline $\begin{array}{l}\frac{0}{0} \\
\frac{0}{2} \\
0 \\
0 \\
0 \\
0 \\
\frac{0}{0} \\
\frac{0}{0} \\
\frac{0}{0} \\
0 \\
0 \\
0 \\
0\end{array}$ & 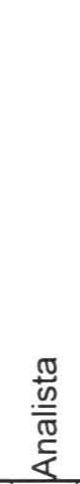 & 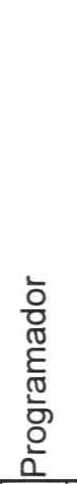 & $\begin{array}{l}0 \\
\stackrel{0}{0} \\
0 \\
0 \\
0 \\
0 \\
0 \\
0 \\
0 \\
0 \\
0 \\
0 \\
0 \\
0\end{array}$ & 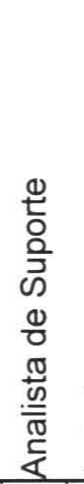 & 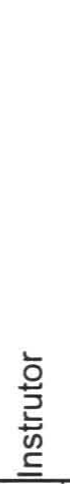 & 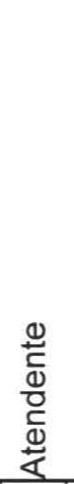 & 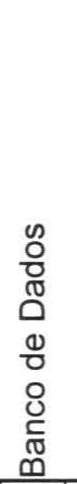 & 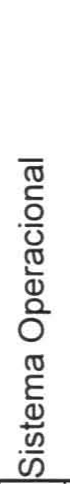 & 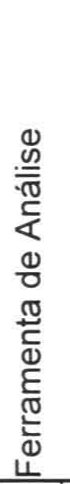 & 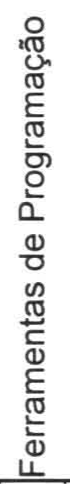 & 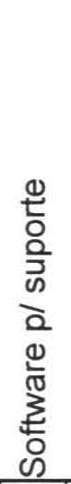 & 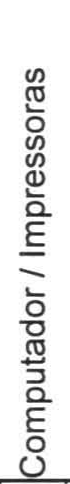 & 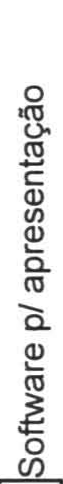 & 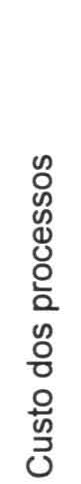 \\
\hline 11 & 3,8 & 0,8 & 1,0 & 0,3 & 0,0 & 0,0 & 0,2 & 0,3 & 0,4 & 0,2 & 0,0 & 0,2 & 0,0 & $8 ?$ \\
\hline 11 & 3,8 & 2,3 & 0,0 & 0,0 & 0,0 & 0,0 & 0,2 & 0,3 & 0,4 & 0,3 & 0,0 & 0,3 & 0,0 & \\
\hline & 1,0 & 6,8 & 0,0 & 0,8 & 0,0 & 0,0 & 0,7 & 0,9 & 0,1 & 0,5 & 0,0 & 0,3 & 0,0 & \\
\hline 11 & 1,3 & 2,3 & 1,0 & 0,0 & 0,0 & 0,0 & 0,1 & 0,1 & 0,2 & 0,2 & 0,0 & 0,2 & 0,0 & \\
\hline 11 & 0,0 & 0,0 & 3,0 & $|0,0|$ & 0,9 & 0,0 & 0,1 & 0,1 & 0,2 & 0,0 & 0,0 & 0,1 & 0,0 & \\
\hline & 0,0 & 0,0 & 1,0 & 0,8 & 2,8 & 0,1 & 0,1 & 0,1 & 0,0 & 0,0 & 0,0 & 0,1 & 0,1 & \\
\hline & 0,0 & 0,0 & 0,0 & 2,3 & 0,3 & 0,7 & 0,1 & 0,1 & 0,0 & 0,0 & 0,1 & 0,2 & 0,0 & \\
\hline
\end{tabular}

\footnotetext{
Desenvolvimento 12,0

Projeto do produto 8,7

Análise dos atributos 8,2

Documentação $\quad 6,4$

Treinamento $\quad 6,1$

Assessoria p/ implantação $\quad 5,7$

Suporte / Manutenção 4,8
}

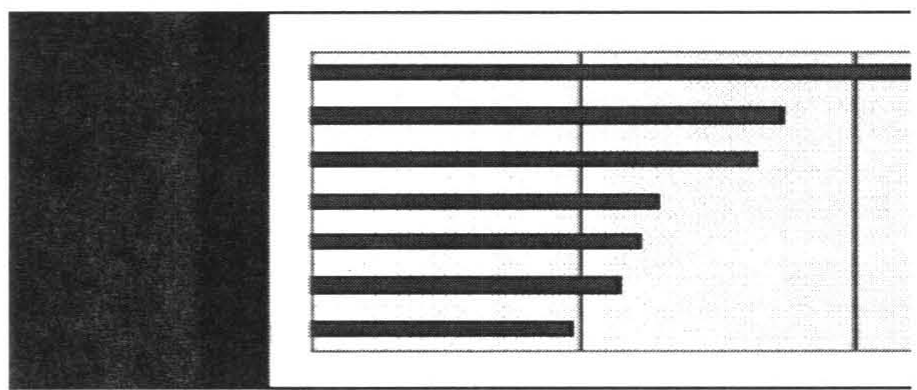

Figura 10: Priorização dos Custos 
Tabela 9: Planejamento da qualidades para o estudo de caso do software de custo.

\begin{tabular}{|c|c|c|c|c|}
\hline ão ( o que ) & Como & $\begin{array}{c}\begin{array}{c}\text { Resultados } \\
\text { Esperados }\end{array} \\
\end{array}$ & Quem & Quando \\
\hline $\begin{array}{l}\text { Desenvolver } \\
\text { gramas e } \\
\text { scedimentos } \\
\text { ra melhorar a } \\
\text { nfiabilidade dos } \\
\text { dos que servem } \\
\text { entrada do } \\
\text { tema de custos } \\
\end{array}$ & $\begin{array}{l}\text { 1. Pesquisar novos métodos e } \\
\text { procedimentos para evitar erros na } \\
\text { entrada de dados } \\
\text { 2. Implementar biblioteca de programas } \\
\text { para validar a entrada de dados } \\
\text { 3. Testar metodologia proposta em } \\
\text { sistema já existente }\end{array}$ & $\begin{array}{l}\text { Que o sistema tenha } \\
\text { informaç̃̃es corretas e } \\
\text { desta forma não mostre } \\
\text { uma imagem errada da } \\
\text { realidade ao usuário }\end{array}$ & $\begin{array}{l}\text { Analista e } \\
\text { Programador }\end{array}$ & $\begin{array}{c}\text { Até } \\
\text { Dezembro } \\
\text { de } 1999\end{array}$ \\
\hline $\begin{array}{l}\text { Desenvolver } \\
\text { nologias e uma } \\
\text { lioteca de } \\
\text { jetos que } \\
\text { jortem o custeio } \\
\mathrm{r} \text { UEP e ABC }\end{array}$ & $\begin{array}{l}\text { 1- } \begin{array}{l}\text { Fazer benchmark com produtos } \\
\text { concorrentes }\end{array} \\
\text { 2- } \begin{array}{l}\text { Pesquisar o funcionamento das técnicas } \\
\text { de custeio ABC e UEP }\end{array} \\
\text { 3- } \begin{array}{l}\text { Desenvolver a análise e projeto dos } \\
\text { objetos }\end{array} \\
\text { 4- Implementar os objetos propostos }\end{array}$ & $\begin{array}{l}\text { Capacitar o sistema a } \\
\text { calcular e apresentar } \\
\text { os custos do cliente } \\
\text { utilizando-se os } \\
\text { métodos ABC e UEP }\end{array}$ & $\begin{array}{l}\text { Analista e } \\
\text { Programador }\end{array}$ & $\begin{array}{c}\text { Até } \\
\text { Março de } \\
2000\end{array}$ \\
\hline $\begin{array}{l}\text { Desenvolver } \\
1 \text { sistema com } \\
\text { I nível de } \\
\text { posta rápido }\end{array}$ & 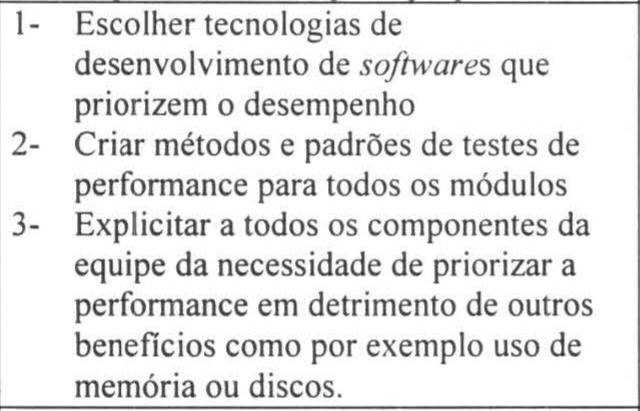 & $\begin{array}{l}\text { Sistema capacitado a } \\
\text { responder as } \\
\text { necessidades de } \\
\text { informações do cliente } \\
\text { de forma rápida. }\end{array}$ & Analista & $\begin{array}{c}\text { Até } \\
\text { Novemb. } \\
\text { de } 1999\end{array}$ \\
\hline $\begin{array}{l}\text { Desenvolver } \\
\text { 1a interface de } \\
\text { :il acesso }\end{array}$ & $\begin{array}{l}\text { 1- } \begin{array}{l}\text { Buscar no mercado bibliotecas de } \\
\text { componentes que auxiliem na } \\
\text { construção de interfaces. }\end{array} \\
\text { 2- } \begin{array}{l}\text { Desenvolver uma técnica de avaliação } \\
\text { da qualidade da interface com a }\end{array} \\
\text { participação efetiva do usuário. } \\
\text { 3- } \begin{array}{l}\text { Pesquisar o uso de novas tecnologias } \\
\text { que facilitem a interface homem- } \\
\text { máquina }\end{array}\end{array}$ & $\begin{array}{l}\text { Aumentar o ganho de } \\
\text { produtividade do } \\
\text { usuário, permitindo } \\
\text { que se tenha uma } \\
\text { melhor interpretação } \\
\text { das informações que } \\
\text { lhe são fornecidas e } \\
\text { um aprendizado rápido } \\
\text { do sistema }\end{array}$ & Analista & $\begin{array}{c}\text { Até } \\
\text { Novemb. } \\
\text { de } 1999\end{array}$ \\
\hline $\begin{array}{l}\text { Desenvolver } \\
\text { erfaces com } \\
\text { tros sistemas } \\
\text { eres de mercado }\end{array}$ & $\begin{aligned} & \text { 1- } \text { Buscar estabelecer parcerias com as } \\
& \text { empresas líderes de mercado (em } \\
& \text { sistemas corporativos) para poder } \\
& \text { integrar-se perfeitamente aos seus } \\
& \text { sistemas. } \\
& \text { 2- } \text { Criar interface de comunicação junto } \\
& \text { com parceiros selecionados. } \\
& \text { 3- } \begin{array}{l}\text { Criar interface de comunicação } \\
\text { genérica para poder se integrar a } \\
\text { qualquer sistema }\end{array} \\
&\end{aligned}$ & $\begin{array}{l}\text { Para o usuário tenha } \\
\text { uma fonte única de } \\
\text { dados (seu sistema } \\
\text { corporativo) e não } \\
\text { tenha que redigitar } \\
\text { dados já existentes em } \\
\text { meio eletrônico. }\end{array}$ & $\begin{array}{l}\text { Gerente de } \\
\text { Projeto / } \\
\text { Analista e } \\
\text { Programador }\end{array}$ & $\begin{array}{l}\text { Até Julho } \\
\text { de } 2000\end{array}$ \\
\hline $\begin{array}{l}\text { Desenvolver } \\
\text { nologias e uma } \\
\text { lioteca de } \\
\text { jetos para } \\
\text { nulação }\end{array}$ & $\begin{array}{l}\text { 1- } \begin{array}{l}\text { Pesquisar técnicas de simulação que } \\
\text { mais se adeguem as simulações de }\end{array} \\
\text { custos } \\
\text { 2- } \begin{array}{l}\text { Desenvolver a análise e projeto dos } \\
\text { objetos para simulação }\end{array} \\
\text { 3- } \text { Implementar os objetos propostos }\end{array}$ & $\begin{array}{l}\text { Capacitar o sistema a } \\
\text { criar cenários futuros }\end{array}$ & $\begin{array}{l}\text { Analista e } \\
\text { Programador }\end{array}$ & $\begin{array}{l}\text { Até Junho } \\
\text { de } 2000\end{array}$ \\
\hline
\end{tabular}




\section{Análise de viabilidade do plano}

O plano contém atividades que são usualmente realizadas no âmbito da softwarehouse e, portanto, não representam dificuldade maior para serem completadas. As ações 1 (procedimentos para a melhoria da confiabilidade), 3 (procedimentos para aumentar a velocidade do sistema) e 4 (desenvolvimento de interfaces de fácil acesso) enquadram-se nesta categoria. São atividades gerais, empreendidas também em outros sistemas.

A ação 2, implantar técnicas de custeio ABC e UEP, exige conhecimentos específicos de métodos de custeio. Uma das pessoas da equipe foi recentemente treinada nesses métodos e possui o conhecimento necessário para levar a termo a tarefa.

A ação 5 (desenvolver interfaces com outros sistemas) é considerada difícil, pois exige intensa comunicação com outras empresas. Contudo, ela é considerada exeqüível, desde que sejam selecionadas empresas interessadas e motivadas para um trabalho em parceria.

A ação 6 irá exigir que a equipe busque conhecimentos em áreas ainda não exploradas, mais especificamente, tecnologias de simulação. Para que essa ação possa ser concluída, será necessário investimentos específicos, ou seja, prever e disponibilizar recursos financeiros e horas-homem.

\section{Considerações sobre o uso do QFD}

A metodologia do QFD era desconhecida da equipe técnica, e foi empregada pela primeira vez neste estudo. A partir da utilização do QFD, observou-se o seguinte:

1. A pesquisa de mercado é uma ferramenta importante, que pode revelar detalhes desconhecidos para a equipe. No início do projeto, a equipe achava que sabia qual o produto a ser desenvolvido; no entanto, após ouvir a voz do cliente, a concepção do produto alterou-se substancialmente. Ouvir a voz do cliente é imperativo.

2. A equipe técnica, por sua vez, também detém muito conhecimento, o qual é revelado gradativamente nas sessões de preenchimento das matrizes. Essas ses se revelaram um importante fórum de aprendizado para todos os participantes.

3. O processo de desenvolvimento de software é um processo criativo, não repetitivo; por isso, o mesmo não é de fácil controle e normalmente não possui controles formais. Em relação e esse aspecto, o QFD contribui efetivamente, pois exige a definição e priorização de indicadores que possibilitam o controle do processo, tanto durante o desenvolvimento do software como nas fases posteriores de manutenção e apoio ao usuário.

4. O uso das priorizações e os gráficos de pareto auxiliaram a identificar e enfatizar os aspectos essenciais associados a qualidade de software. Toda a equipe possui um conhecimento mais aprofundado e mais homogêneo referente as características, módulos e processos críticos.

5. O desenvolvimento de software sem dúvida exige técnicas específicas relacionadas à programação $\mathrm{e}$ integração dos diversos módulos, mas o uso do QFD na gestão do desenvolvimento do produto representa uma importante vantagem.

6. Como desvantagem ou dificuldade observada durante a utilização do QFD, pode-se citar a necessidade de reuniões formais, dificeis de serem agendadas. No entanto, espera-se que na medida em que o método seja incorporado pela empresa, a sua rotina modifique-se no sentido de acomodar reuniões regulares da equipe de desenvolvimento.

\section{Conclusões}

Este trabalho apresentou uma aplicação do QFD voltada para o desenvolvimento de um software de custos. Foi utilizado um modelo conceitual que envolve o desdobramento de qualidade, partes, processos, recursos e custos. O estudo de caso foi apresentado em todas as suas etapas: da pesquisa de mercado ao planejamento da qualidade do produto. Também foi feita uma análise crítica evidenciando as vantagens do uso da metodologia, a partir da percepção da equipe, a qual utilizava o QFD pela primeira vez. 
O uso do QFD mostrou vantagens importantes, ajudando a definir as características principais que o sistema deve possuir. Normalmente os analistas de sistemas privilegiam as características técnicas do sistema, uma visão limitada, que frequentemente não contempla o universo de características valorizadas pelos usuários. O QFD contribuiu para estruturar as atividades de desenvolvimento do software. Ele soma-se as demais ferramentas de análise de sistemas existentes, auxiliando para que o sistema contemple as necessidades do usuário e exija o mínimo possível de reprogramação.

\section{Agradecimentos}

Os autores deste trabalho manifestam seu agradecimento aos alunos do Mestrado Profissionalizante da Escola de Engenharia da UFRGS que contribuíram na realização deste trabalho, especialmente nas etapas de coleta de dados e no preenchimento das matrizes: André Kayser, Claiton Avrela Pessoa, José Carlos da Costa Trujillo, Luis Fernando Cruz da Costa, Ricardo Dal Pont e Rogério Monteiro.

\section{Referências Bibliográficas}

AKAO, Yoji - Desdobramento das diretrizes para o sucesso do TQM, Editora Bookmam, São Paulo, 1997.

DALE, B.G. \& MACHOWSKI, F. - Quality cost collection in the development of software: a methodology. Quality Engineering, v.11, n.3, p. 457-462, 1999.

GHIYA, K.K., BAHILL, A.T. \& CHAPMANN, W.L. - QFD: Validating robustness. Quality Engineering, v.11, n.4, p. 593-611, 1999.

GUSTAFSSON, A. \& JOHNSON, M.D. - Bridging the quality satisfaction gap. Quality Management Journal, v.4, n.3, p. 27-43, 1997.
KING, R - Listening to the Voice of the Customer: Using the Quality Function Deployment System. National Productivity Review, New York, v.6, n.3, p.277-281, 1987.

ISO 9000-3: Quality management and quality assurance standards. Parte 3: Guidelines for the application of ISO 9001 to the development, supply, and maintenance of software. Geneva, Switzerland: International organization for Standardization, 1991.

RIBEIRO, J.L., ECHEVESTE, M.E. \& DANILEVICZ, A.M.F. - A utilização do QFD na otimização de produtos, processos e serviços. Programa de Pós-graduação em Engenharia de Produção, Porto Alegre RS, 2000.

SULLIVAN, L.P. - Quality Function Deployment. Quality Progress, v. 19, n.6, p. 39-50, 1986.

URSEY, M.W. \& DOOLEY, K.J. - The dimensions of software quality. Quality Management Journal, v.3, n.3, p.67-86.

URSEY, M.W. \& DOOLEY, K.J. - The measurement of consumer attitudes concerning software quality. Quality Management Journal, v.5, n.2, p.42-57.

YUKI, M.M. - Quality Function Deployment: QFD. Instituto Latino Americano de Tecnologia, IBM, São Paulo, 1994. 105p. 


\section{ANEXO I - QUESTIONÁRIO ABERTO}

1- Qual a sua função na empresa?

( ) Diretor ( ) Gerente ( ) Supervisor ( ) Outro

2- Qual o faturamento mensal da sua empresa?

$\mathrm{R} \$$

3- Sua empresa possui um sistema de custos?

( ) Não

( ) $\operatorname{Sim}$

É Informatizado ( ) ou Manual ( )

4- Que informações de custos você considera importante para sua tomada de decisões?

5- Quais as características você considera importante na aquisição de um software de custo?

6- Atualmente, existem alguns software no mercado. Quais são as principais falhas que você considera nestes sistemas?

7- Quais as melhorias que poderiam ser adicionadas?

8- Quais as características que fariam você adquirir um software de custo?

9- Qual a forma de divulgação que você acha mais eficiente? 


\section{Anexo II - Questionário fechado}

$\mathrm{N}^{\circ}$ do Questionário

Entrevistador

Data

Empresa

Somos uma empresa especializada em software gerencial e estamos desenvolvendo um novo sistema de gerenciamento de custos. Para tanto a sua opinião é importante para definir as características que o software deverá possuir. Agradecemos a sua participação.

Obrigado!

Ordene de 1 (mais importante) a 5 (menos importante os três itens que você considera mais importante para o sistema de custos (alguns espaços ficarão em branco).

1- Na aquisição de um software de custos, o que você considera mais importante ?

[ ] - Interface de fácil acesso

[ ]-Performance do sistema

[ ]-Métodos de análise avançados

[ ] - Método de custeio

[ ]-Manutenção e suporte

[ ]-Preço

[ ]-Personalização

[ ] - Atualização em tempo real

[ ]-Confiabilidade das informaç̃̃es

[ ]-Segurança dos dados

[ ] - Uso de novas tecnologias de informática

Para as questðes 2 - 11, ordene de 1 (mais importante) a 3 (menos importante) os três itens que você considera mais importante para o sistema de custos (alguns espaços ficarão em branco).

2- Em relação a interface quais as características mais importantes ?

[ ] - Uso de interface gráfica (Windows)

[ ]-Interface personalizável as necessidades individuais

[ ]-Visualização das informações em forma de gráficos sempre que possível

[ ] - Utilização de atalhos para navegação

[ ]-Comunicação com outros sistemas

3- Em relação a performance o que você considera mais importante

[ ] - Velocidade na entrada dos dados

[ ]-Velocidade nas consultas

[ ] - Velocidade nos processamentos das informações (cálculos )

[ ] - Velocidade na implantação do software

[ ] - Velocidade de adequação do software a uma nova necessidade de informação

4- Dos métodos de análise avançados citados abaixo qual você acha mais importante?

[ ] - Capacidade de desenvolvimento de cenários

[ ] - Capacidade de quantificar custo da qualidade

[ ]-Capacidade de calcular possíveis ganhos com melhoria de processos

[ ]-Capacidade de quantificar perdas do processo

[ ] - Capacidade de quantificar lucros ou perdas associadas a um determinado produto/cliente

5- Em relação ao método de custeio citados, enumere o que você gostaria que estivesse disponível no sistema:

[ ] - Centro de custos (absorçâo total / absorção parcial)

[ ] - TOC (Teoria das restrições)

[ ] - ABC (Custeio baseado em atividades)

[ ] - UEP (Unidede de esforço padrão)

[ ] - Custo padrão

6 Quanto aos serviços prestados pelo fabricante do software, o que você considera mais importante:

[ ] - Assessoria e treinamento personalizado na área de custos

] - Treinamento formal explicando como utilizar o software

[ ]-Suporte por internet

] - Suporte por telefone

[ ]-Suporte pessoal

[ ] - Help on-line (manuais eletrônicos) com exemplos e exercícios

7 Em relação a personalização do sistema o que você considera mais importante?

[ ] - A personalização do software deve ser feita pela software-house

[ ]-O sistema deve permitir que o próprio usuário faça as suas personalizações

[ ] - $\mathrm{O}$ atendimento de suporte e manutenção deve ser personalizado a sua empresa

[ ]-Permitir a personalização por parte do usuário das telas de entrada dos dados

[ ] - Permitir a personalização das consultas e análise de custos por parte do usuário 
7 A atualização do sistema de forma on-line deve priorizar quais informações?

[ ]-possuir as informações associadas aos preços de matérias primas on-line

[ ] - possuir as informações associadas aos gastos/receitas dos processos da empresa de forma on-line

[ ] - formação e avaliação do preço de venda on-line

[ ] - formação do custo/hora setor ou máquina de forma on-line

[ ] - avaliação da produtividade e ociosidade dos processos on-line

8 Em relação a confiabilidade das informações do sistema

[ ] - o sistema deve ser inteligente p/detecção de erros nos dados e informações

[ ] - o sistema deve ser capaz de alocar custos sem distorções

[ ] - o sistema deve trabalhar com informações exatas

[ ] - o sistema deve possuir informações condizentes com a realidade (não necessariamente exatas)

[ ] - o sistema deve possuir indicadores que quantificam o grau de confiabilidade da fonte das informações apresentadas pelo mesmo.

9 Em relação a segurança de acesso e a integridade dos dados o que você considera mais importante

[ ]- Back-up on-line dos dados

[ ] - Segurança de acesso controlado por senhas

[ ] - Segurança contra perda de dados por queda do sistema

[ ]-Segurança contra vírus

[ ] - Segurança contra Hackers (alto nível de segurança contra especialistas em invadir sistemas)

10 Quanto a novas tecnologias quais das tecnologias abaixo você gostaria que o sistema possuísse

[ ] - Possibilidade do sistema ser acessado pela Internet de qualquer local do planeta

[ ] - Reconhecimento de voz tornando a interface mais "humana"

[ ]-Capacidade de rodar em computadores de mão como o Palm-Pilot (computação móvel)

[ ] - Possuir a habilidade de coletar informações externas a empresa (informações estruturadas e não estruturadas da bolsa de valores, jornais, fornecedores, clientes, concorrentes...)

[ ] - Possuir algoritmos de inteligência artificial para melhor analisar as informações.

12 - Se você já possui sistema de custos, classifique o seu grau de satisfação em relação aos itens abaixo:

\begin{tabular}{|l|l|l|l|l|l|}
\hline & $\begin{array}{c}\text { Muito } \\
\text { satisfeito }\end{array}$ & Satisfeito & Indiferente & insatisfeito & $\begin{array}{c}\text { Muito } \\
\text { insatisfeito }\end{array}$ \\
\hline Gastos com o sistema & & & & & \\
\hline Atendimento & & & & & \\
\hline Velocidade de resposta & & & & & \\
\hline Confiabilidade das informações do sistema & & & & & \\
\hline Personalização rápida e eficiente & & & & & \\
\hline Interface com o usuário & & & & & \\
\hline Apresentação dos indicadores de decisão & & & & & \\
\hline Método de custeio & & & & & \\
\hline Adequação a novas tecnologias & & & & & \\
\hline Desenvolvimento de cenários futuros & & & & & \\
\hline
\end{tabular}

Para terminar, gostaríamos de ter algumas informações sobre você.

Qual o faturamento mensal da sua empresa.

Qual seu cargo:

Qual método de custos que sua empresa utiliza atualmente. 